\title{
Rancang Bangun Alat Monitoring Pulsa Listrik Rumah Tinggal Berbasis Raspberry Pi Dengan Notifikasi Sms Dan E-mail
}

\author{
Sherli Wahyuni Dwi Afriani' ${ }^{1}$ Ibnu Ziad, Suroso ${ }^{2}$ \\ Fakultas Teknik Elektro, Teknik Telekomunikasi, Politeknik Negeri Sriwijaya, Palembang, Indonesia \\ Jl.Srijaya Negara, Bukit Lama, Kec. Ilir Barat I, Kota Palembang 30139 \\ sherliwahyuni22@gmail.com, Ibnupoltek1@gmail.com,osorus11@gmail.com
}

\begin{abstract}
In this design presents the design of electric pulse monitoring devices in residential homes. This tool is designed using the Raspberry Pi as a microprosessor. In the design process, this tool uses a light sensor (Light Dependent Resistor) to read the change of lights from green to red on the electric token, Camera Pi NoIR to take pictures of electric pulses, and SIM 800 to send SMS notifications. With the programming language used in the design of this tool is Language C. In monitoring the use of electric pulses, this tool is also designed to be able to send notifications automatically when the use of electric pulses has reached the minimum limit. Notifications sent will be received in the form of sms and email by the homeowner. It is expected that this tool can provide convenience to homeowners to monitor the use of electric pulses from a distance when the house is empty.
\end{abstract}

Keywords: Raspberry Pi, Sensor LDR (Light Dependent Resistor), Kamera Pi NoIR, SIM $800 \mathrm{~L}$

Abstrak
Pada perancangan ini menyajikan perancangan alat monitoring pulsa listrik pada rumah tinggal. Alat ini dirancang dengan memanfaatkan Raspberry Pi sebagai mikroprosesor. Pada proses perancangannya, alat ini menggunakan sensor cahaya (Light Dependent Resistor) untuk membaca perubahan lampu dari hijau ke merah pada token listrik, Kamera Pi NoIR untuk mengambil gambar pulsa listrik, dan SIM 800 untuk mengirimkan notifikasi sms. Dengan bahasa pemrograman yang digunakan dalam perancangan alat ini adalah Bahasa C. Dalam memonitoring penggunaan pulsa listrik, alat ini juga dirancang untuk dapat mengirimkan isecara otomatis apabila penggunaan pulsa listrik telah mencapai batas minimum. Notifikasi yang dikirimkan akan diterima dalam bentuk sms dan email oleh pemilik rumah. Diharapkan dengan adanya alat ini dapat memberi kemudahan pada pemilik rumah untuk memonitoring penggunaan pulsa listrik dari jarak jauh ketika rumah dalam keadaan kosong.

Kata kunci: Raspberry Pi, Sensor LDR (Light Dependent Resistor), Kamera Pi NoIR, SIM 800L

\section{PENDAHULUAN}

Salah satu kebutuhan pokok yang sangat penting untuk manusia di era modern sekarang ini adalah listrik, ini dikarenakan sebagian besar peralatan rumah tangga, kantor ataupun industri menggunakan listrik sebagai sumber daya dalam penerapannya. Teknologi prabayar ini merupakan teknologi terbaru memudahkan pelanggan dalam mengontrol biaya pengeluaran listrik serta dapat 
dirancang sesuai dengan anggaran yang kita inginkan. Namun dengan teknologi prabayar, habisnya kuota listrik hanya dapat diketahui jika pemilik sedang berada dirumah dengan aktifnya buzzer sebagai alarm. Sedangkan bila pemilik rumah sedang berada diluar rumah tidak dapat mengetahuinya karena berada diluar jangkauan suara buzzer.

Pada penelitian ini sistem Monitoring Pulsa Listrik merupakan sebuah sistem yang dapat memonitoring pulsa listrik secara otomatis mengirimkan notifikasi. Dimana sistem ini akan mempermudah untuk memonitoring pulsa listrik dari jarak jarak jauh dan memudahkan pemilik rumah mengetahui jumlah pulsa listrik saat rumah dalam keadaan kosong melalui notifikasi sms dan email

\section{METODOLOGI PENELITIAN}

Tahapan dalam perancangan ini yaitu desain hardware yang dirancang sederhana dengan kemampuan handal serta harga yang sangat terjangkau. Sistem ini kemudian digambarkan melalui diagram blok secara keseluruhan. Sedangkan software dirancang untuk memonitoring pulsa listrik melalui system penyimpanan database. Kinerja pengiriman informasi dari alat yang besinergi dengan kamera yang mengirim informasi ke server, serta dari server akan mengirimkan informasi kepada pemilik rumah melalui $\operatorname{sms}[1]$.

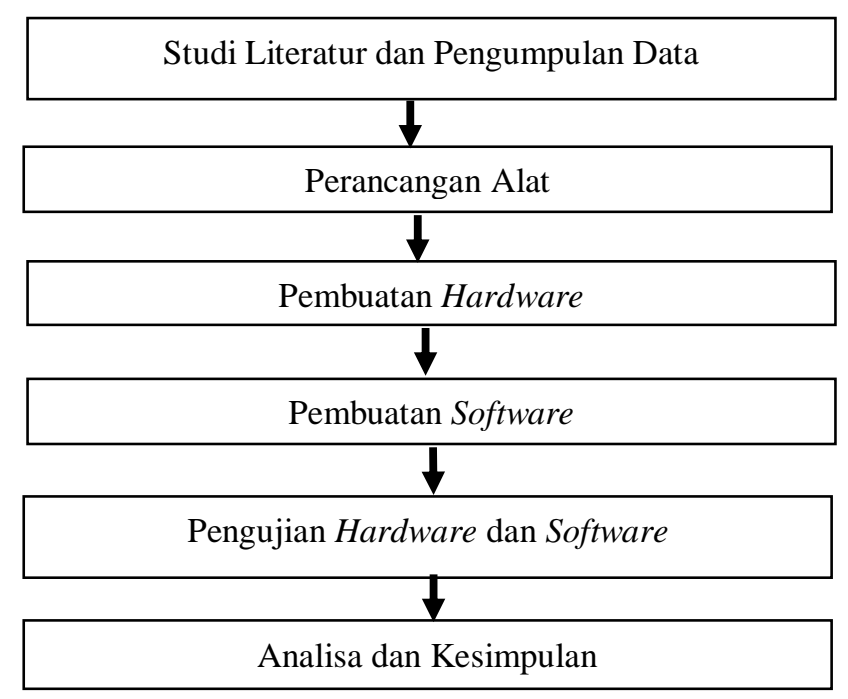

Gambar 1. Diagram Alur Penelitian

Adapun bahasa pemrograman yang digunakan adalah bahasa C dengan software Putty dan Netbeans. Putty digunakan untuk melakukan inisialisasi dari berbagai komponen yang digunakan serta memanggil perintah awal dari koding yang telah dibuat. Sedangkan Netbeans merupakan implementasi bahasa C sebagai tempat melakukan pengkodingan komponen. Serta Software lain yang digunakan berupa Sublime Text, XAMPP, serta PhPmyAdmin 


\section{HASIL DAN PEMBAHASAN}

Perancangan perangkat keras ini ditempatkan pada meteran listrik meliputi beberapa komponen seperti kamera, mikrokontroler, dan modul GSM. Komponen tersebut akan terintegrasi seperti pada blok diagram Gambar 2. Kamera yang digunakan pada sistem yang dirancang adalah Kamera Pi NoIR yang tersambung dengan Raspberry Pi menggunakan konektor CSI pada Raspberry Pi[2] Kamera merupakan parameter penting untuk megetahui daya listrik yang digunakan oleh pelanggan. Mikroprosessor digunakan untuk memproses data penggunaan daya listrik yang digunakan pelanggan. Pada perancangan alat monitoring pulsa listrik rumah tinggal ini menggunakan mikroprosesor Raspberry Pi. Raspberry Pi merupakan suatu mikroprosesor yang dikembangkan oleh Raspberry Pi Foundation yang berukuran kecil seperti kartu kredit sehingga dapat disebut sebagai computer micro. Computer single board ini dikembangkan untuk mengajarkan tentang ilmu computer dan pemrograman diseluruh dunia kepada anak-anak siswa sekolah dasar [3].

Maka perlu pemrograman kecil pada perancangan perangkat lunak pada mikroprosesor untuk menangkap data meteran. Agar dapat berkomunikasi dengan pelanggan maka modul GSM dipasang pada meteran listrik yang selanjutnya dihubungkan dengan handphone pelanggan. Fungsi dari Modul GSM ini mampu melakukan proses transceiver suatu pesan singkat atau SMS. Selain itu Modul GSM juga berfungsi sebagai peralatan yang menghubungkan mikroprosesor dan jaringan GSM dalam suatu aplikasi nirkabel. Sehingga sistem yang dirancang nantinya dapat dimonitoring dari jarak jauh oleh pemilik sistem dengan menggunakan jaringan GSM sebagai media aksesnya [4]. Pada perancangan ini menghasilkan sebuah alat yang dapat memonitoring pulsa listrik dari jarak jauh dengan mengirimkan notifikasi secara otomatis bila pulsa listrik telah mencapai batas minimum.

\subsection{Tampilan Hasil Perancangan}

a) Tampilan Alat Monitoring Pulsa Listrik

Pada tampilan ini berupa alat monitoring pulsa listrik beserta komponen berupa Raspberry Pi, Sensor LDR, Kamera Pi NoIR, SIM 800, Jumper secukupnya, serta USB sebagai komponen pendukung. Alat ini menggunakan Power Supply sebagai catu daya nya.

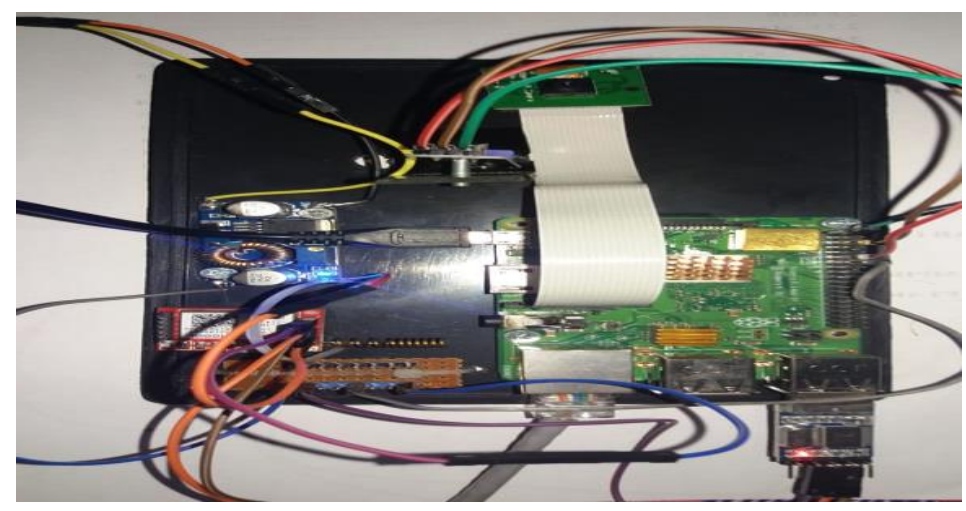

Gambar 2. Tampilan Alat Monitoring 
b) Tampilan Notifikasi Email

Tampilan ini berupa notifikasi Email telah diterima di handphone pemilik rumah. Tampilan ini menunjukkan jika sensor telah terbaca dan secara otomatis akan mengirimkan pemberitahuan berupa gambar ke email pemilik rumah yang telah terdaftar.

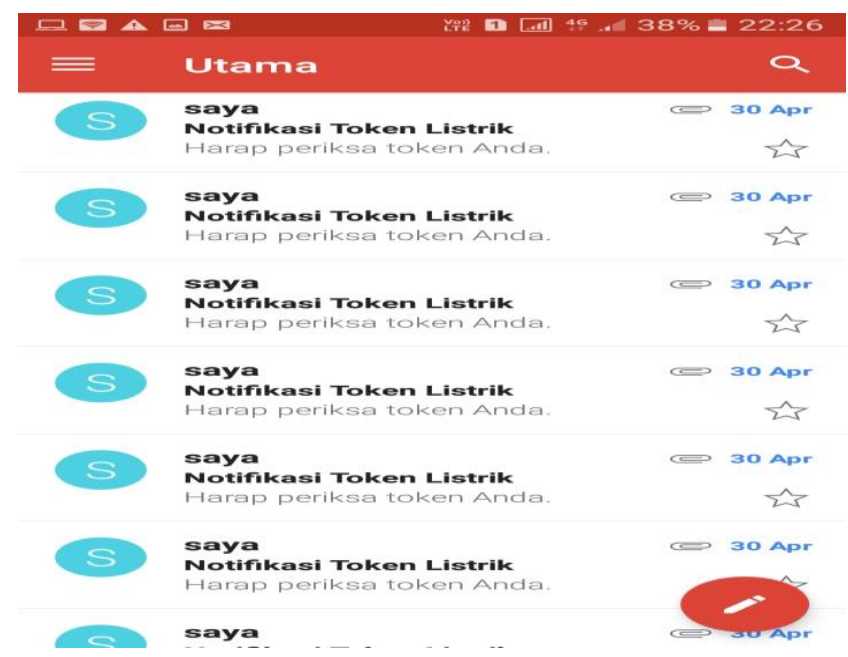

Gambar 3. Tampilan Notifikasi Email
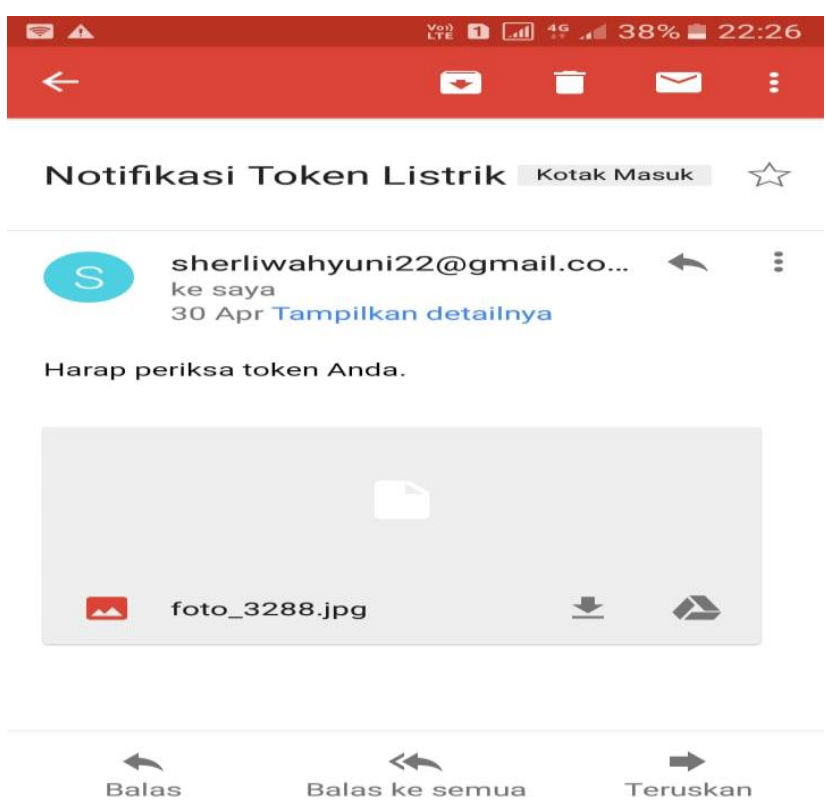

Gambar 4. Tampilan Isi Notifikasi Email

c) Tampilan Notifikasi SMS

Tampilan notifikasi SMS telah diterima di handphone pemilik rumah. Tampilan ini menunjukkan sebuah notifikasi berupa sms ke handphone pemilik rumah ketika pulsa listrik telah mencapai batas minimum. 


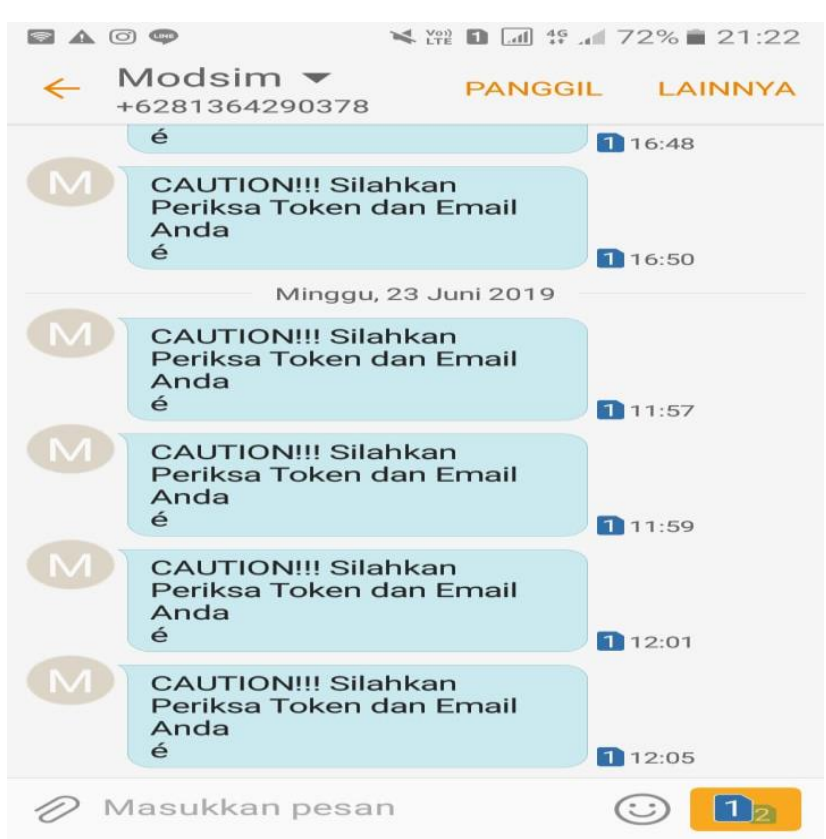

Gambar 5. Tampilan Notifikasi SMS

\subsection{Pengujian Fungsional}

Berikut adalah hasil pengujian alat :

Tabel 1. Hasil Pengujian Alat

\begin{tabular}{|l|l|l|l|}
\hline \multirow{2}{*}{ No. } & \multirow{2}{*}{ Yang Diuji } & \multicolumn{2}{|l|}{ Hasil Pengujian } \\
\cline { 3 - 4 } & & Berhasil & Gagal \\
\hline 1. & Sensor $L D R$ & V & - \\
\hline 2. & Kamera Pi NoIR & V & - \\
\hline 3. & Notifikasi SMS & v & - \\
\hline 4. & Notifikasi Email & v & - \\
\hline
\end{tabular}

\section{SIMPULAN}

Berikut adalah hasil dari beberapa kesimpulan;

a) Perancangan perangkat keras (Hardware) menghasilkan alat yang terdiri dari beberapa alat seperti mikroprosesor, sensor cahaya, kamera, dan baterai.

b) Perancangan perangkat lunak (Software) menghasilkan sebuah perancangan untuk mengatur data masukan dan keluaran dari sistem ini.

c) Dari keseluruhan perancangan Perangkat Keras (Hardware) dan Perangkat Lunak (Software) ini menghasilkan sebuah aplikasi monitoring berupa data pulsa listrik yang kemudian dikirimkan berupa notifikasi ke Handphone pelanggan.

d) Notifikasi yang dikirimkan berupa informasi pulsa listrik yang kemudian dikirimkan ke Handphone pelanggan ketika berada jauh dari rumah, yaitu berupa notifikasi $e$-mail dan notifikasi $s m s$. 
Jurnal Riset Sistem Informasi Dan Teknik Informatika (JURASIK)

Volume (4) Juli 2019, pp 89-94

ISSN: 2527-5771/EISSN: 2549-7839

http://tunasbangsa.ac.id/ejurnal/index.php/jurasik

\section{DAFTAR PUSTAKA}

[1] Devi Indah Pujiana, Ade Silvia Handayani, Aryanti, 2017. "Perancangan WSN dalam Sistem Monitoring Lingkungan”, Vol.3, No.1 (ISBN : 979-587-705-4).

[2] M. Yolandah, 2015. Raspberry Pi, Palembang : Politeknik Negeri Sriwijaya

[3] Helmi Muhammad Shadiq, Sudjadi, Darjat, "Perancangan Kamera Pemantau Nirkabel Menggunakan Raspberry Pi Model B”, Vol.3, No.4, Desember 2014 (ISSN: 2302-9927,547).

[4] Hadi Fakarilmi, Hafidudin, Mas Sarwoko, "Perancangan dan Implementasi Sistem Kontrol dan Monitoring KWH Meter Digital Menggunakan SMS Gateway", Vol.2, No.2, Agustus 2015 (ISSN: 2355-9365). 